\title{
Three-dimensional Reconstruction and Porosity Calculation of Ceramic Coating: Nondestructive X-ray Computed Tomography
}

\author{
ZHANG Zhifeng, WANG Fengjuan, WU Shengping, JIANG Jinyang \\ (Jiangsu Key Laboratory for Construction Materials, Southeast University, Nanjing 211189, China)
}

\begin{abstract}
Ceramic coatings can effectively prevent the corrosion of steel bars in marine environments. In this study, we prepared phosphate ceramic coatings on the surface of carbon steel. X-ray diffraction and X-ray fluorescence were used to analyze the phase structure and composition of the ceramic and the results show that the main crystal composition of ceramic is $\mathrm{P}_{2} \mathrm{O}_{5}$ and $\mathrm{SiO}_{2}$. Scanning electron microscopy was used to characterize the morphology of the surface and the section and results showed that the surface was cracked, and the thickness of ceramic was $349 \mu \mathrm{m}$. Meanwhile, a number of high-resolution images of internal structure of solids were obtained by non-destructive X-ray computed tomography (X-CT). Matlab and Mimics software were used to conduct the three-dimensional reconstruction of the CT images. Matrix and holes are distinguished by threshold segmentation in grayscale images, and the porosity of the ceramic coatings was calculated to be $14.0 \%$. In addition, mercury intrusion porosimetry was used to verify the calculation results. Therefore, X-CT can be a useful and reliable tool for the visualization of the internal structure of ceramic coatings.
\end{abstract}

Key words: ceramics; porosity; X-CT technology; 3D reconstruction

Reinforced concrete structures are widely used due to their high performance and low cost of their constituent raw materials ${ }^{[1]}$. Owing to construction of a large amounts of infrastructure, consumption of cement is increasing yearly as the amount of concrete and steel rebar.

Owing to the presence of holes in concrete, aggressive ions penetrate the concrete and reach the surface of steel rebar, which destroy the passive film on the steel surface ${ }^{[2]}$. In particular, under an offshore aggressive environment, dry and wet cycling conditions accelerate the transmission of harmful ions. The corroded steel bars undergo stress expansion and the fluffy corrosion products reduce adhesion to the concrete, which cause premature deterioration of civil infrastructures, leading to serious consequences $^{[3]}$. Therefore, various methods have been used to isolate ions and protect carbon steel, such as ceramic coatings $^{[4]}$, green inhibitors ${ }^{[5]}$, corrosion-resistant steel bars $^{[6]}$, and photogenerated electron cathodic protection ${ }^{[7]}$. Among these methods, protective ceramic coatings are the most applied and studied methods. Tang, et al. ${ }^{[8]}$ prepared different enamel coatings, and they found that three types of intact ceramic coatings significantly outperformed fusion-bonded expoxy coatings. However, due to the presence of microscopic isolated pores, the properties of the three ceramics are not completely identical. Traditional test methods such as scanning electronic microscopy (SEM) can only characterize the shape of the hole in the ceramic surface and cannot calculate the specific porosity of the entire ceramic. Moreover, mercury intrusion porosimetry (MIP) has been widely used to determine the pore-size distribution (PSD) for most materials, from which a wide range of pore sizes can be found ${ }^{[9]}$. However MIP can only detect the local zone of the sample and the tests depend on the assumption that the pores are cylindrical, which cannot reflect the actual pore pattern $^{[10]}$. Therefore, it is necessary and vital to develop a new approach to calculate the porosity of ceramic coatings and to devise a new and improved model of the relationship between the transmission rate of ions and the porosity of ceramic coatings.

$\mathrm{X}$-ray computed tomography $(\mathrm{X}-\mathrm{CT})$ is mostly used in medicine, in which computer-processed X-ray data are used to construct images of bone, the brain, organs, etc ${ }^{[11]}$. Two-(2D) or three-dimensional (3D) reconstruction of a

Received date: 2019-10-21; Revised date: $2019-12-18$

Foundation item: National Basic Research Program of China (973 Program, 2015CB65510)

Biography: ZHANG Zhifeng(1989-), male, PhD candidate. E-mail: zzf_0201@126.com 张志锋(1989-), 男, 博士研究生. E-mail: zzf_0201@126.com

Corresponding author: JIANG Jinyang, professor. E-mail: jiangjinyang16@163.com 蒋金洋, 教授. E-mail: jiangjinyang16@163.com 
test structure can be achieved by computer technology, which makes the internal structure able to be more intuitively explored. Therefore, it is convenient to analyze the pore structure of ceramic solid materials non-destructively ${ }^{[12]}$. In previous research, Yang, et al. ${ }^{[13]}$ revealed the in situ tracking of water transport in cement paste using X-CT, in which $\mathrm{CsCl}$ was added to the water to enhance the contrast. 3D representations of ceramics are achievable at different pore sizes and provide a way to observe the evolution of pores, which is useful in understanding the failure mechanism of ceramic coatings ${ }^{[14]}$.

In this study, X-CT was applied to porosity calculations of ceramic coatings, which is an important parameter for the transport of aggressive ions inside ceramic structures. 2D and 3D images were generated and the threshold segmentation technique was used to distinguish the pores and substrate. Furthermore, MIP was used to study the porosity and pore size distribution, which provide mutual authentication of the X-CT test results of the porosity of ceramic coatings.

\section{Experiments}

\subsection{Materials}

A phosphate ceramic coating was supplied by Eoncoat Coating (Eoncoat Coating Technology Co. Ltd., Beijing, China) and was used without any further alteration. Q235 carbon steel was used and its content is shown in Table $1^{[5]}$. First, the carbon steel with the size of $\Phi 20 \mathrm{~mm} \times 10 \mathrm{~mm}$, was sand-blasted to remove the surface oxide and achieve a rough surface. Then, the ceramic coating was sprayed onto the surface 10 times to prepare the coating. The resolution of X-CT images is related with the sample size, and smaller size provides higher definition. Therefore a piece of ceramic coating was peeled off from the carbon steel coating as test sample to obtain the highresolution picture.

Before the test, the ceramic bulk was dried at $50{ }^{\circ} \mathrm{C}$ in air oven for $3 \mathrm{~h}$. After cooling to room temperature, epoxy resin was used to wrap and fix the ceramic. The ceramic was then ground in agate mortar to obtain the powder used in X-ray diffraction (XRD), X-ray fluorescence (XRF) and high-resolution transmission electron microscopy (HRTEM) experiments.

\subsection{Characterization}

The phase structure was detected by XRD (Bruker D8 Discover) from $10^{\circ}$ to $80^{\circ}$ at $0.02\left(^{\circ}\right) / \mathrm{s}$. The chemical

Table 1 Composition of carbon steel Q235

\begin{tabular}{ccccccc}
\hline Element & $\mathrm{C}$ & $\mathrm{Mn}$ & $\mathrm{Si}$ & $\mathrm{S}$ & $\mathrm{P}$ & $\mathrm{Fe}$ \\
\hline $\begin{array}{l}\text { Composi- } \\
\text { tion/wt\% }\end{array}$ & $0.14-0.22$ & $0.30-0.65$ & $<0.60$ & $<0.05$ & $<0.45$ & Balance \\
\hline
\end{tabular}

composition was determined using XRF (Bruker S4 Pioneer) at $40 \mathrm{kV}$ and $100 \mathrm{~mA}^{[15]}$. SEM (Navo Nano SEM450, $30 \mathrm{kV}$ ) with Energy Dispersive X-ray Spectroscopy (EDS) was used to determine the morphology of the ceramic surface and section ${ }^{[16-17]}$. TEM and HRTEM were used to get the morphology of nanosize oxide particles. MIP was performed on a Micrometrics Autopore IV 9500. A contact angle of $130^{\circ}$ was assumed. The pressure ranged from $1.5 \times 10^{4} \mathrm{~Pa}$ to $6.1 \times 10^{4} \mathrm{~Pa}$. CT scan test was performed on a Y. CT Precision S X-CT system (YXLON, Germany) with resolution of $1024 \times 1024$ pixels $^{[18]}$. The images were pre-processed in MatLab R2016a software (MathWorks, USA), and the 2D or 3D image reconstructions and porosity calculated using Mimics research software.

\section{Results and discussion}

\subsection{Phase composition analysis}

\subsubsection{XRD analysis}

The phase composition and crystal structure of the as-prepared ceramic were examined by XRD. As shown in Fig. 1, the main constituents of the ceramic are $\mathrm{P}_{2} \mathrm{O}_{5}$ (JCPDS 23-1301), $\mathrm{SiO}_{2}$ (JCPDS 27-0605), which correspond to the lattice plane of (111), (111). There are two crystal structures of $\mathrm{TiO}_{2}$ in ceramic, which are ascribed to the lattice planes of (110) and (101) for rutile $\mathrm{TiO}_{2}$ (JCPDS 21-1276) and anatase $\mathrm{TiO}_{2}$ (JCPDS 21-1272), respectively ${ }^{[19]}$. Also, there are a small amount of $\mathrm{CaO}$, $\mathrm{Fe}_{2} \mathrm{O}_{3}$ and $\mathrm{MgO}_{4}$, with JCPDS 50-1575, 40-1139 and 27-0759, respectively. Furthermore, the novel type of zeolite in the system of $\mathrm{K}_{2} \mathrm{O}-\mathrm{Na}_{2} \mathrm{O}-\mathrm{Al}_{2} \mathrm{O}_{3}-\mathrm{SiO}_{2}-\mathrm{H}_{2} \mathrm{O}$ with JCPDS 43-0050 was detected.

\subsubsection{XRF analysis}

The XRF results of the as-prepared ceramic coatings, expressed in oxide form, are presented in Table 2. The $\mathrm{XRF}$ analysis showed that the main phase composition of ceramic is $\mathrm{P}_{2} \mathrm{O}_{5}, \mathrm{SiO}_{2}, \mathrm{~K}_{2} \mathrm{O}$, and $\mathrm{MgO}$ with a total amount of $81.55 \mathrm{wt} \%$. And a small amount of $\mathrm{Al}_{2} \mathrm{O}_{3}, \mathrm{CaO}$, and $\mathrm{TiO}_{2}$, and the balance being $\mathrm{Na}_{2} \mathrm{O} / \mathrm{SO}_{3} / \mathrm{Fe}_{2} \mathrm{O}_{3} / \mathrm{ZnO}$. The

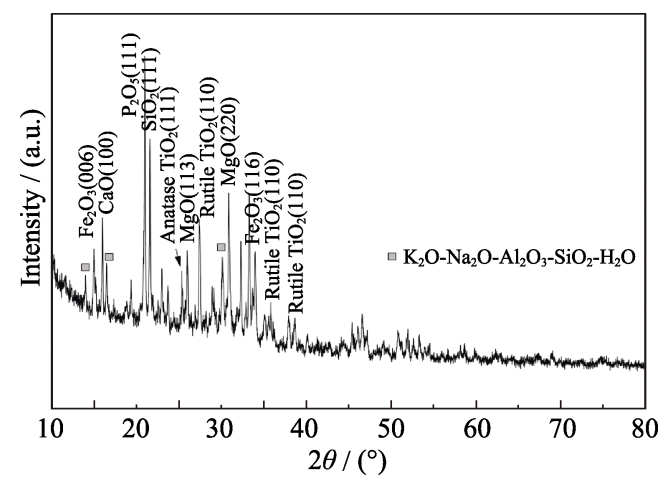

Fig. 1 XRD pattern of as-prepared ceramic coating 
Table 2 Chemical analysis determined by XRF of the as-prepared ceramic coating

\begin{tabular}{cc}
\hline Oxide compound & Proportion $/ \mathrm{wt} \%$ \\
\hline $\mathrm{MgO}$ & 10.38 \\
$\mathrm{Al}_{2} \mathrm{O}_{3}$ & 6.64 \\
$\mathrm{SiO}_{2}$ & 22.56 \\
$\mathrm{P}_{2} \mathrm{O}_{5}$ & 29.75 \\
$\mathrm{~K}_{2} \mathrm{O}$ & 18.86 \\
$\mathrm{CaO}$ & 8.06 \\
$\mathrm{TiO}_{2}$ & 2.44 \\
Balance $\left(\mathrm{Na}_{2} \mathrm{O} / \mathrm{SO}_{3} / \mathrm{Fe}_{2} \mathrm{O}_{3} / \mathrm{ZnO}\right)$ & 1.31 \\
\hline
\end{tabular}

main reason for the detection of oxides of $\mathrm{Al}_{2} \mathrm{O}_{3}$ and $\mathrm{ZnO}$ in XRF test but not in XRD test is that the content of oxide is too small to be detected. The XRF results are completely consistent with the results of the XRD analysis.

\subsection{SEM analysis}

SEM is a useful technology to study the morphology of the surfaces and sections of the ceramic coatings. Fig. 2(a) shows the surface SEM image of the ceramic coating. It can be seen that the ceramic coating was a stable whole and the surface is rough. However, the oxide particles are not packed densely, resulting in the pore between the oxide particles. Inset is EDS analysis of area \#1 shown in Fig. 2(a), which reveals that the main constituents of the ceramic are $\mathrm{P}, \mathrm{Si}, \mathrm{Mg}, \mathrm{Fe}$ and $\mathrm{K}$, in good agreement with the XRD and XRF analysis results. Furthermore, the section morphology of the ceramic and steel
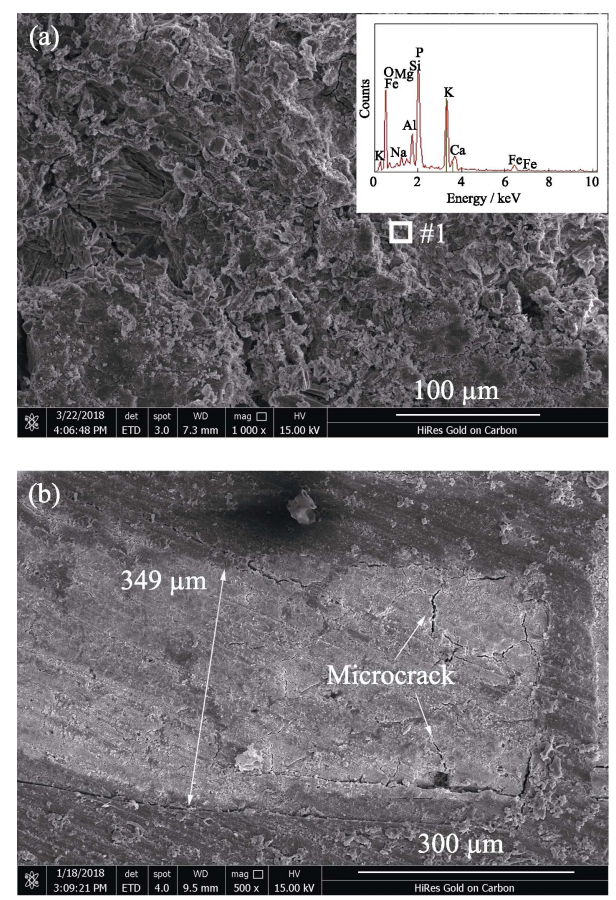

Fig. 2 Surface (a) and section (b) SEM images of the as-prepared ceramic coating

Inset in (a) is the EDS analysis of area \#1 is shown in Fig. 2(b), demonstrating that the thickness of the ceramic coating is $349 \mu \mathrm{m}$ and, moreover, that the ceramic coating is tightly bonded to the steel bars. In addition, microcracks are seen in the section, which may be caused by the difference in thermal expansion coefficients between the ceramic coating and the steel.

\subsection{TEM and HRTEM analysis}

TEM and HRTEM images of the ceramic coating are shown in Fig. 3 which provide more detailed latticeparameter information regarding the oxide in the ceramic coating. As shown in Fig. 3(a), the coating powder has a plate-like structure, which has been superimposed to form a cluster. Fig. 3(b) clearly shows two sets of lattice fringes with lattice spacings of 0.327 and $0.285 \mathrm{~nm}$, corresponding to the (110) and (420) planes of $\mathrm{TiO}_{2}$ and $\mathrm{P}_{2} \mathrm{O}_{5}$, respectively, which is consistent with XRD results.

\subsection{D reconstruction and porosity analysis}

The evolution of ceramic-coating porosity was monitored by the X-CT system. First, eight hundred highresolution $\mathrm{CT}$ high resolution images were obtained after the X-CT test. Pre-processing was performed using Matlab to remove the edge portion of images, such as epoxy resin. The raw X-CT picture is shown in Fig. 4(a) and cropped by Matlab according the red dotted line. The cutting pictures were imported in Mimics Research software. In Mimics software, we can distinguish the hole structure and substrate by threshold segmentation of grayscale value, and results of the division for the end face and side face are shown in Figs. 4(b, c), in which the green part represents the hole and the yellow part represents the substrate. Then 2D pictures with segmentation of grayscale value were 3D reconstructed by Mimics Research software immediately. 3D reconstructions of the hole structure and substrate can be formed by overlay analysis of the high resolution images and are shown in Figs. 4(d, e), respectively. In addition, the volumes of the hole and substrate can be calculated in Mimics software by counting the total amount of the green and yellow areas and marked as $V_{\text {hole }}$ and $V_{\text {sub }}$, respectively. Then the porosity can be calculated by the following equation:
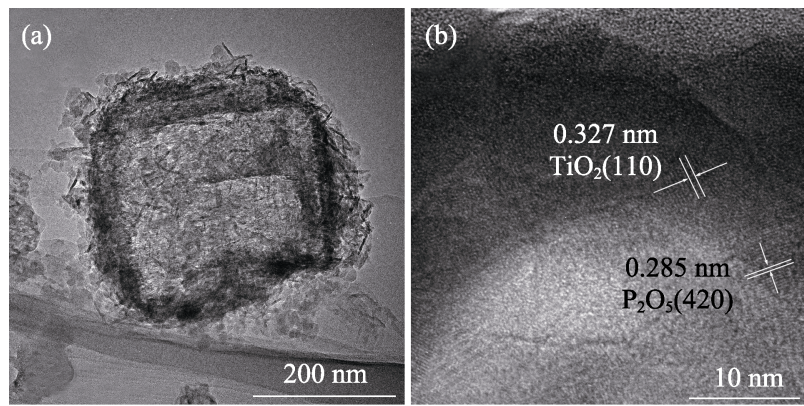

Fig. 3 (a) TEM and (b) HRTEM images of ceramic coating 


$$
P=\frac{V_{\text {hole }}}{V_{\text {hole }}+V_{\text {sub }}} \times 100 \%
$$

where $P$ is the porosity of ceramic coating. In this work the calculated value of $P$ is $14.0 \%$. A lower porosity of ceramic leads to a lower transmission rate for the aggressive ions. Therefore, a lower porosity ceramic coating can effectively prevent the migration of chloride ions to the surface of the carbon steel and avoid corroding the steel rebar.

MIP test was used to further verify the porosity of ceramic, and the pore structure and pore size distribution (PSD) were shown in Fig. 5. There are two critical pore diameters, one is less than $10 \mathrm{~nm}$, and another is between $1 \mu \mathrm{m}$ to $10 \mu \mathrm{m}$. Pore diameter less than $10 \mathrm{~nm}$ is the gel pores of oxide substrate ${ }^{[20]}$. And the highest peak in the pore entry size distribution from $1 \mu \mathrm{m}$ to $10 \mu \mathrm{m}$ is the gap between the oxides, which is shown in Fig. 5. The porosity obtained by the MIP is $12.275 \%$, which is close to the calculated result by the X-CT. The MIP test confirms that the X-CT can be a fast and non-destructive method to measure the porosity.


Fig. 4 CT images of ceramic coating

(a) Raw X-CT image; (b, c) Threshold segmentation of (b) hole structure and (c) substrate structure; (d, e) 3D reconstruction of (d) hole and (e) substrate

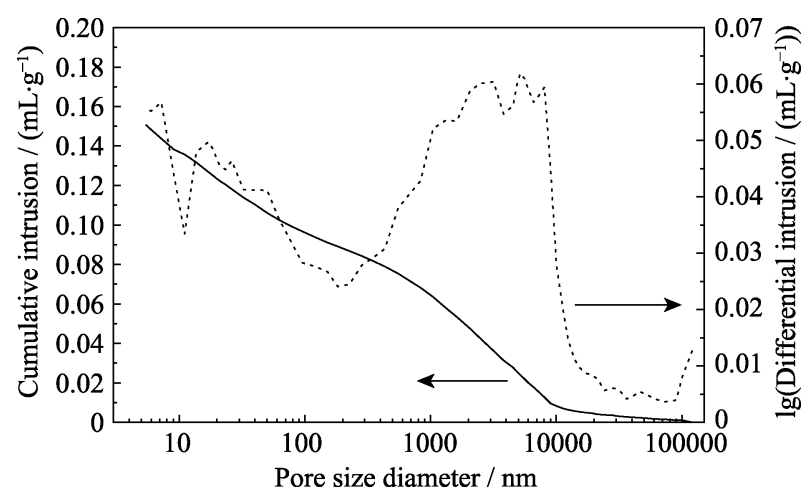

Fig. 5 Pore size distribution test by MIP: cumulative intrusion $(\mathrm{mL} / \mathrm{g})$ and $\lg \left(\right.$ differential intrusion $\left./\left(\mathrm{mL} \cdot \mathrm{g}^{-1}\right)\right)$

\section{Conclusions}

Ceramic coatings are very effective materials that provide corrosion-protection for steel. However, due to the different thermal expansion coefficient of the steel matrix, microcracks and holes are present in ceramic coatings. X-CT can reveal the internal hole structure nondestructively, i.e., the hole and substrate are distinguished by threshold segmentation. 3D reconstruction the hole and substrate structure can be achieved by analyzing the CT images with Matlab and Mimics. By calculating of hole volume and the volume of the substrate, the porosity of the ceramic coating was calculated as $14 \%$. By the MIP test, the porosity of ceramic coating is $12.275 \%$, which is close to the calculation result of X-CT. The main pore structure is the gel pores of oxide and gap between the oxides. Therefore, it can be seen that X-CT technology is a useful and reliable technique to calculate the porosity of solid material.

\section{References:}

[1] YANG J J, HAI R, WU K R. Effect of ettringite structural transformation on expansive behavior of expansion cement. Journal of Inorganic Materials, 2003, 18(1): 136-142.

[2] LÜ J L, JIN H J, LIANG T X. The effect of electrochemical nitridationon the corrosion resistance of the passive films formed on the 2205 duplex stainless steel. Materials Letters, 2019, 256: 1-4.

[3] ZHAO Y P, LIU Y, LIU Q, et al. Icephobicity studies of superhydrophobic coatings on concrete via spray method. Materials Letters, 2018, 233: 263-266.

[4] WANG P S. Study on Preparation and Critical Properties of a New Type of Steel Bars Coated with Micro/Nano Ceramics. Nanjing: Master Thesis of Southeast University, 2016.

[5] ZHANG Z F, WANG F J, LIU Y, et al. Molecule adsorption and corrosion mechanism of steel under protection of inhibitor in a simulated concrete solution with $3.5 \% \mathrm{NaCl}$. RSC Advances, 2018, 8: 20648.

[6] JIANG J Y, CHU H Y, LIU YAO, et al. Galvanic corrosion of duplex corrosion-resistant steel rebars under carbonated concrete conditions. RSC Advances, 2018, 8: 16626.

[7] WEI Q Y, WANG X T, NING X B, et al. Characteristics and anticorrosion performance of $\mathrm{WSe}_{2} / \mathrm{TiO}_{2}$ nanocomposite materials for 304 stainless steel. Surface and Coatings Technology, 2018, 352: 26-32.

[8] TANG F J, CHEN G D, BROWN R K, et al. Corrosion resistance and mechanism of steel rebar coated with three types of enamel. Corrosion Science, 2012, 59: 157-168.

[9] CUI D, BANTHIA N, WANG Q N, et al. Investigation on porosity of partly carbonated paste specimens blended with fly ash through dual CT scans. Construction and Building Materials, 2019, 196: 692-702.

[10] LUBELli B, WINTER D A M, POST J A, et al. Cryo-FIB-SEM and MIP study of porosity and pore size distribution of bentonite and kaolin at different moisture contents. Applied Clay Science, 2013, 80-81: 358-365.

[11] COLLINGWOOD J F, ADAMS F. Chemical imaging analysis of the brain with X-ray methods. Spectrochimica Acta Part B: Atomic 
Spectroscopy, 2017, 130: 101-118.

[12] HERMANEK P, CARMIGNATO S. Porosity measurements by X-ray computed tomography: accuracy evaluation using a calibrated object. Precision Engineering, 2017, 49: 377-387.

[13] YANG L, ZHANG Y S, LIU Z Y, et al. In-situ tracking of water transport in cement paste using X-ray computed tomography combined with $\mathrm{CsCl}$ enhancing. Materials Letters, 2015, 160: 381-383.

[14] ZHU W, CAI X N, YANG L, et al. The evolution of pores in thermal barrier coatings under volcanic ash corrosion using X-ray computed tomography. Surface and Coatings Technology, 2019, 357: 372-378.

[15] ZHENG Y F, ZHANG L L, WANG K, et al. Microstructure characterization and luminescent property of mixed spinel $\mathrm{Zn}_{6} \mathrm{Ga}_{8} \mathrm{TiO}_{20}: \mathrm{Cr}^{3+}$ phosphors. Journal of Inorganic Materials, 2018, 33(1): 9-13.

[16] LI Y T, CHEN L, GUO Y L, et al. Preparation and characterization of $\mathrm{WO}_{3} / \mathrm{TiO}_{2}$ hollow microsphere composites with catalytic activity in dark. Chemical Engineering Journal, 2012, 181-182: 734-739.

[17] ZHANG X F, ZHANG G H, MENG Y, et al. Photocatalytic degradation of methylene blue by schiff-base cobalt modified $\mathrm{CoCr}$ layered double hydroxides. Journal of Inorganic Materials, 2019, 34(9): 974-982.

[18] WAN K S, LI G, WANG S H, et al. 3D full field study of drying shrinkage of foam concrete. Cement and Concrete Composite, 2017, 82: 217-226.

[19] ZHANG Z Y, SANG L X, LU L P, et al. Preparation of $\mathrm{TiO}_{2}$ nanotube arrays and their photoelectrochemical properties. Journal of Inorganic Materials, 2010, 25(11): 1145-1149.

[20] KANG S H, HONG S G, MOON J. The effect of superabsorbent polymer on various scale of pore structure in ultra-high performance concrete. Construction and Building Materials, 2018, 172: $29-40$.

\title{
X-CT 无损测试技术用于陶瓷涂层三维重构和孔隙率计算
}

\author{
张志锋，王凤娟，武胜萍，蒋金洋 \\ (东南大学 江苏省建筑材料重点实验室, 南京 211189)
}

摘 要: 陶瓷涂层对海工环境中的钢筋有着较好的保护作用。在碳钢表面喷涂磷酸盐陶瓷涂层, 采用 XRD 和 XRF 对陶瓷涂层的物相组成进行分析。结果表明: 实验用陶瓷的主要晶相成分为 $\mathrm{P}_{2} \mathrm{O}_{5}$ 与 $\mathrm{SiO}_{2}$ 。采用 $\mathrm{SEM}$ 对陶瓷的表 面和截面形貌进行观察, 发现陶瓷涂层内存在微裂纹, 涂层的厚度约为 $349 \mu \mathrm{m}$ 。采用 X-CT 测试可以得到陶瓷内部 结构的高清图像, 并利用 Matlab 和 Mimics 软件对高清图像进行三维重构。此外通过阈值分割技术, 将 CT 图像内 的孔与基体灰度值区分开来, 并计算得到陶瓷涂层的孔隙率为 $14 \%$, 并采用压录测试技术对测试结果进行验证。研 究认为 X-CT 无损测试是一种建立陶瓷涂层内可视化孔结构分析的有效工具。

关 键 词: 陶瓷; 孔隙率; X-CT 技术; 三维重构

中图分类号: TQ174 文献标识码: A 